\title{
Resilience and self-care of elderly people with diabetes mellitus
}

\author{
Resiliência e autocuidado de pessoas idosas com diabetes mellitus
}

Mateus Carneiro Vicente ${ }^{1}$, Cleane Rosa Ribeiro da Silva ${ }^{1}$, Cláudia Jeane Lopes Pimenta ${ }^{1}$, Maria Cristina Lins Oliveira Frazão ${ }^{1}$, Tatiana Ferreira da Costa $^{1}$, Kátia Neyla de Freitas Macedo Costa ${ }^{1}$

Objective: to associate resilience levels and self-care activities in elderly people with diabetes mellitus. Methods: a cross-sectional study was carried out with 96 elderly patients hospitalized for complications of diabetes mellitus in medical and surgical clinics of a university hospital. Data were collected through interviews, Resilience Scale, and Diabetes Self-Care Activities Questionnaire, being analyzed by descriptive and inferential statistics. Results: elderly patients with low resilience demonstrated statistically significant higher averages of week days dedicated to self-care activities such as in the axes medication, foot care, and blood glucose monitoring. Conclusion: a statistical association between resilience and self-care was identified in the areas of Medication, Foot Care and Blood glucose monitoring, with evidence of higher averages among elderly patients who showed low resilience, which shows a lower adherence of these individuals to non-pharmacological activities.

Descriptors: Resilience, Psychological; Self Care; Aged; Diabetes Mellitus.

Objetivo: associar os níveis de resiliência e as atividades de autocuidado em pessoas idosas com diabetes mellitus. Métodos: estudo transversal, realizado com 96 idosos hospitalizados por complicação do diabetes mellitus em clínicas médica e cirúrgica de hospital universitário. Coleta de dados realizada por meio de entrevista, Escala de Resiliência e Questionário de Atividades de Autocuidado com o Diabetes, sendo analisados por estatística descritiva e inferencial. Resultados: idosos com baixa resiliência demonstraram maiores médias de dias na semana destinados às atividades de autocuidado nos eixos medicação, cuidado com os pés e monitorização da glicemia, sendo evidenciada significância estatística. Conclusão: identificou-se associação estatística entre a resiliência e o autocuidado nos domínios Medicação, Cuidado com os pés e Monitorização da glicemia, com evidência de maiores médias entre os idosos com baixa resiliência, o que demonstra menor adesão desses indivíduos às atividades não farmacológicas.

Descritores: Resiliência Psicológica; Autocuidado; Idoso; Diabetes Mellitus.

${ }^{1}$ Universidade Federal da Paraíba. João Pessoa, PB, Brazil.

Corresponding author: Cláudia Jeane Lopes Pimenta

Rua Luiz Prímola da Silva, 30, Bancários. CEP: 58051-340. João Pessoa, PB, Brazil. E-mail: claudinhajeane8@hotmail.com 


\section{Introduction}

Non-communicable chronic diseases represent a public health problem worldwide, among which diabetes mellitus stands out due to its high morbidity and mortality rates and high annual costs with control and treatment, especially in the elderly population ${ }^{(1)}$. According to data from the International Diabetes Federation, more than 425 million people are currently living with this disease and one third of them are elderly people, estimated to increase to 693 million by $2045^{(2)}$.

The increase in the incidence of diabetes mellitus is related to individual and collective factors, present in contemporary society, such as the process of population aging, increasing urbanization, the adoption of inadequate diet with little fruit and vegetable intake, sedentary lifestyle, obesity, and constant exposure to stress ${ }^{(2)}$. Consequently, older people are more vulnerable to the development of diabetes mellitus and are at high risk of complications, which, in most cases, can be prevented through the adoption of simple self-care measures ${ }^{(3)}$.

Glycemic control poses a great challenge for diabetes mellitus patients because it requires daily effort on their part and their relatives to adopt healthy behaviors, in order to modify the lifestyle and carry out self-care practices directed to adequate food, regular practice of physical activity, blood glucose monitoring, foot care, medication use, and more frequent health evaluations ${ }^{(4)}$.

In this sense, because of the innumerable changes implied in the new routine of the person when diabetes mellitus is found out, resilient attitudes become fundamental, to cope with adversity and to adapt to the limitations imposed by the disease ${ }^{(5-6)}$. A study carried out with users who had diabetes mellitus from eight health centers in Belo Horizonte, Minas Gerais, Brazil, observed that when the individuals feel resilient before their health condition, they present a greater motivation to care for their wellbeing, and this has positive impacts on their quality of life and disease control ${ }^{(7)}$.

Resilience is defined as a process that overarches the creation of resources and the ability to withstand negative physiological responses to traumatic situations, whether sudden events such as disasters or even changes triggered by chronic conditions, in which the stressor will be present throughout the rest of the life ${ }^{(8)}$. In elderly people with diabetes mellitus, resilience can act as an important tool for health maintenance and prevention of complications, promoting the adequate motivation for adherence to self-care practices and lessening negative feelings that may hamper disease control ${ }^{[4,7]}$.

The assistance provided by health professionals, especially nurses, also plays a relevant role in the empowerment of elderly patients regarding self-care. They can intervene through strategies that allow the understanding of subjective, emotional, social and environmental factors that affect the patient's ability to carry out self-care, which helps in the establishment of individual goals and the systematic follow-up of each case in a comprehensive and individualized manner $^{(1,9)}$.

In view of the above, the objective of this research was to associate levels of resilience and self-care activities in elderly people with diabetes mellitus.

\section{Methods}

Cross-sectional study carried out in the medical and surgical clinics of a university hospital located in the city of João Pessoa, Paraíba, Brazil.

The study population consisted of elderly people hospitalized for complications of diabetes mellitus at the referred hospital in 2015, totaling 126 individuals. Sample size was defined using calculation for finite populations, with a confidence interval of $95.0 \%$ ( $\alpha=0.05$, which gives $Z_{0.05 / 2}=1.96$ ), an estimated prevalence of $50.0 \%(p=0.50)$, and a margin of error of $5.0 \%$ 
(Error=0.05), which corresponded to 96 participants.

The inclusion criteria were: age 60 years or older; medical diagnosis for any type of diabetes mellitus in at least the last six months; and admission to the medical or surgical clinic in the last 24 hours prior to data collection. Elderly patients who presented a diagnosis of dementia, speech disorders and/or decreased auditory acuity that impeded communication during data collection, as indicated by the companion, were excluded from the study.

Data collection was performed between November 2016 and February 2017 through interviews which a semi-structured instrument to survey sociodemographic and clinical data, including the following variables: gender, age, marital status, education, religion, social security status, personal and family income, city of origin, type of diabetes mellitus, pharmacological therapy, self-reported health status, smoking, alcoholism, and difficulty of living with the disease. In addition, the Resilience Scale and the Diabetes Self-Care Activities Questionnaire were also used.

The Resilience Scale has been adapted and validated for Brazil. It presents a total of 25 items, whose answers vary from 1 (totally disagree) to 7 (totally agree), being composed of three factors: Factor 1 - resolution of actions and values (15 items); Factor 2 - independence and determination (4 items); and Factor 3 - self-confidence and ability to adapt to situations (6 items). The final score ranges from 25 to 175 points $^{(10)}$.

Because the scale does not present a specific classification for resilience, and the only indication is that a score equal to or greater than 147 indicates high levels of resilience, we chose to distribute the values into quartiles. Thus, scores of up to 111 points correspond to low resilience; from 112 to 146 indicated moderate resilience; and values greater or equal to 147 points characterized a high level of resilience.

To evaluate self-care with diabetes mellitus, the Diabetes Self-Care Activities Questionnaire was used. This questionnaire has been adapted and vali- dated for Brazil. It has 18 items distributed into seven domains: General diet, Specific diet, Physical activity, Blood glucose monitoring, Foot care, Medication use, and Smoking. The analysis of adherence considers the number of times a given activity was performed during the last seven days prior to data collection, assigning a score to each item that varies from 0 to 7 ; 0 indicates the least desirable and 7 the most favorable, with exception for the domain Specific diet that addresses the consumption of fat-rich and sugar-rich foods, whose values are reversed ${ }^{(11)}$.

Desirable self-care behavior corresponded to cases where the average obtained in the activities was above four, which comprises the number of days of the week in which the self-care practices were performed. This cut-off point was also adopted for items whose values are inverted, with values below four indicating a satisfactory self-care behavior ${ }^{(3)}$.

The collected data were compiled and stored in the Microsoft Office Excel software and subsequently imported into the Statistical Package for the Social Sciences, version 22.0, to perform descriptive statistical analyses. The Kolmogorov-Smirnov test was used to check the normality of data in the resilience and self-care domains; these variables presented a non-normal distribution. The Kruskal-Wallis test was used to check for association between variables, because they were non-parametric variables. A statistically significant association was considered when $\mathrm{p} \leq 0.05$.

The study complied with the norms of Resolution 466/12 on research involving human beings and was approved by the Research Ethics Committee of the Hospital Universitário Lauro Wanderley, according to Opinion no $1,581,777$.

\section{Results}

With respect to the sociodemographic characteristics of the elderly patients, there was a higher frequency of women (55.2\%), aged 60-69 years (60.4\%), 
with a mean age of 68.58 years $( \pm 6.93)$, married or living with a partner $(54.2 \%)$, with incomplete elementary school (36.5\%), Catholics $(72.9 \%)$, retired (71.9\%), and with individual and family income between $\mathrm{R} \$ 880$ and $\mathrm{R} \$ 1,760$ (81.3\% and $85.4 \%$, respectively).

Regarding health conditions, the majority of the participants presented diabetes mellitus type 2 (96.9\%), mean time of diagnosis of 5.71 years $( \pm 2.19)$, with diabetic foot as the most frequent complication (35.7\%), used only oral hypoglycemic as pharmacological therapy (45.8\%), evaluated their health as regular (61.5\%), did not smoke (93.8\%), did not consume alcoholic beverages $(99.0 \%)$, and reported facing difficulties of living with the disease $(40.6 \%)$. The evaluation of resilience indicated that the elderly patients had moderate (57.3\%) and low (34.3\%) levels of resilience.

Diabetes self-care activities had high adherence averages in almost all domains, except in relation to Physical activity, with the highest average found for General diet $6.43( \pm 1.22)$ and Foot care $6.18( \pm 1.76)$. The activities of eating high-fat (0.71) and sugar-rich $(0.62)$ foods showed low averages, due to the inversion of values necessary for analysis of the scale, indicating that the elderly participants had a high adherence to self-care, since they consumed these foods a few times during the week. Regarding smoking, it was identified that the majority of the elderly had not smoked in the last seven days (92.7\%).

The relationship between self-care and resilience of the study participants showed that the patients with low resilience had statistically significant $(\mathrm{p} \leq 0.05)$ higher averages of week days dedicated to self-care activities in Medication (6.90 \pm 0.370 ), Foot care $(6.75 \pm 1.267)$ and Blood glucose monitoring $(6.40 \pm 1.323)$ (Table 1$)$.
Table 1 - Distribution of data regarding the relationship between diabetes self-care activities during seven days of the week and resilience levels

\begin{tabular}{lcccc}
\hline \multirow{2}{*}{ Self-care } & \multicolumn{4}{c}{ Resilience } \\
\cline { 2 - 4 } & Low & Moderate & High & p* \\
\cline { 2 - 4 } & Mean \pm SD & Mean \pm SD & Mean \pm SD & \\
\hline General diet & $6.26 \pm 1.487$ & $6.48 \pm 1.145$ & $6.50 \pm 1.109$ & 0.920 \\
Specific diet & $2.42 \pm 1.188$ & $2.70 \pm 1.120$ & $2.74 \pm 1.008$ & 0.120 \\
Physical activity & $0.26 \pm 0.792$ & $0.36 \pm 0.987$ & $1.56 \pm 2.705$ & 0.149 \\
Blood glucose & mo- \\
nitoring & $6.40 \pm 1.323$ & $5.39 \pm 2.129$ & $6.14 \pm 1.571$ & 0.050 \\
Foot care & $6.75 \pm 1.267$ & $6.07 \pm 1.678$ & $5.83 \pm 2.211$ & 0.012 \\
Medicine use & $6.90 \pm 0.370$ & $5.39 \pm 1.621$ & $5.15 \pm 2.218$ & 0.004 \\
\hline *Kruskal-Wallis Test; SD: standard deviation & & &
\end{tabular}

\section{Discussion}

The present study presents limitations related to the absence of associations on self-care activities and resilience with metabolic control, therapeutic regimen, disease time, associated morbidities and sociodemographic data, taking into account that these variables may have influenced the results. Another limitation was the fact that the study was conducted in a single hospital, which does not allow the generalization of the findings.

It was observed that the majority of the elderly presented moderate levels of resilience, which could be related to the typical characteristics of this population, the time of living with the disease, and the acceptance of the difficulties resulting from diabetes mellitus. Overcoming obstacles can provide the necessary support to deal with the adversities inherent to this morbidity, favoring the adaptation to changes to maintain glycemic stability ${ }^{(2,6)}$.

Health professionals, and particularly nurses, should include interventions to foster increased re- 
silience in the care plan of elderly diabetes mellitus patients. To that end, three determinants of this construct need to be considered: individual characteristics, family environment supported by affective bonds, and social support network to assist in coping with stressors $^{(12)}$.

Studies indicate that when elderly people face hostile situations, they tend to prioritize pleasurable experiences and minimize conflicts, because the burden of life experience becomes a determining factor for adjustment and overcoming of difficult circumstances experienced by this population ${ }^{(4,6)}$.

The process of acceptance of a chronic disease such as diabetes mellitus represents a great challenge for the affected person, especially for young people, because the symptoms and complications interfere significantly in their health and daily routine ${ }^{(6)}$. On the other hand, for older people, this process takes place more spontaneously, resulting mainly from the resilience acquired throughout time due to the need to adapt to usual limitations imposed by aging ${ }^{(7)}$.

Among the diabetes self-care activities, greater adherence was observed in the General diet and Foot care domains. Physical activity showed lower adherence, with an average close to zero. It is noteworthy that the elderly participants had satisfactory adherence in Specific diet, whose score was inverted, and values lower than four showed beneficial adherence, with reduced consumption of fatty and sweet foods.

Healthy diet is one of the most relevant changes to maintain adequate blood glucose levels; it is in fact imperative for elderly people with diabetes mellitus. A healthy diet helps considerably in the treatment of the disease, promoting the control and prevention of diseases. However, this practice needs to be guided by health professionals, who must evaluate the routine of the patients, their energy needs, and their monthly income $^{(13)}$.

The Foot care domain showed high adherence among the elderly subjects interviewed. This aspect stands out as an important self-care activity, since it prevents the development of vascular problems and diabetic foot, which frequently lead to impaired functional capacity, besides increased risk of amputations, hospitalizations and death ${ }^{(1,14)}$.

The Physical activity domain showed averages below one, indicating that the elderly performed physical activity at most one day per week. This represents a risk to health and to the quality of life of these individuals. Neglect of physical activity makes diabetes mellitus patients more vulnerable. Physical activity can effectively reduce the need for pharmacological treatment, improve metabolic control through increased sensitivity to insulin action and glucose uptake, promote weight loss, and reduce the risk of cardiovascular diseases ${ }^{(15)}$. Physical activity should be performed more than three times a week, because the action increases insulin sensitivity, which does not remain for more than 72 hours $^{(16)}$.

Regarding the relationship between self-care activities and resilience, the elderly with low resilience obtained higher averages in the activities of Medication use, Foot care and Blood glucose monitoring. This finding may be related to the belief that drug treatment is more effective than preventive measures because of the rapid effect on glycemic levels, thus causing greater adherence to these activities ${ }^{(17)}$. Associated with this, monitoring of glycemia provides immediate and accurate results, and therefore performed more frequently, especially among individuals who have not yet adapted to changes in lifestyle habits $^{(18)}$.

The significant association between low resilience and the Foot care domain may be due to the presence of lower limb injuries present in the majority of the elderly in this study, a fact that urges them to perform care, due to the risk of complications. Besides, this practice does not take much time or causes greater interferences in daily life ${ }^{(19)}$. In this sense, nurses should advise older people with diabetes mellitus about foot care, including measures such as examining the feet daily, paying attention to their sensitivity, 
avoiding excessive moisture, keeping the skin hydrated, trimming the nails carefully, and protecting the feet with adequate footwear, preventing injuries that can generate losses and increase the risk of amputations and impairments in functional capacity ${ }^{(1)}$.

Resilience is a dynamic process that favors the adaptation to the health needs of people with diabetes mellitus. An expanded understanding of its relationship with adherence to self-care, especially among the elderly population, is necessary ${ }^{(8,20)}$. Health professionals, especially nurses, should therefore promote resilience among the elderly population with diabetes mellitus, in order to enhance self-care in the face of the needs arising from this chronic disease, as well as to strengthen the coping capacity in the face of adversities brought about by the aging process ${ }^{(7)}$.

\section{Conclusion}

A statistical association was identified between resilience and self-care in the areas of Medication use, Foot Care, and Blood glucose monitoring, with evidence of higher averages among elderly people with low resilience, thus showing less adherence among these participants to non-pharmacological activities.

\section{Acknowledgements}

To the Conselho Nacional de Desenvolvimento Científico e Tecnológico and the Coordenação de Aperfeiçoamento de Pessoal de Nível Superior.

\section{Collaborations}

Vicente MC and Frazão MCLO contributed in the analysis, interpretation of data, and writing of the article. Silva CRR and Pimenta CJL collaborated in the conception and design and critical review of intellectual content. Costa TF and Costa KNFM assisted in the critical review of the intellectual content and approval of the final version to be published.

\section{References}

1. Carvalho SL, Ferreira MA, Medeiros JMP, Queiroga ACF, Moreira TR, Negreiros FDS. Conversations map: an educational strategy in the care of elderly people with diabetes mellitus. Rev Bras Enferm. 2018; 71(suppl 2):981-6. doi: http://dx.doi. org/10.1590/0034-7167-2017-0064

2. International Diabetes Federation. Diabetes Atlas [Internet]. 2017 [cited Jan 24, 2019]. Available from: https://www.idf.org/e-library/ epidemiology-research/diabetes-atlas.html

3. Eid LP, Leopoldino SAD, Oller GASAO, Pompeo DA, Martins MA, Gueroni LPB. Factors related to self-care activities of patients with type 2 diabtes mellitus. Esc Anna Nery. 2018; 22(4):e20180046. doi:http://dx.doi.org/10.1590/2177-9465EAN-2018-0046

4. Almeida VCD, Araújo ST, Negreiros FDS, Aguiar MIF, Moreira TR, Crispim APP. Micro and macro vascular complications in the people with type 2 diabetes mellitus in outpatient care. Rev Rene. 2017; 18(6):787-93. doi: http://dx.doi. org/10.15253/2175-6783.2017000600012

5. Frazão MCLO, Pimenta CJL, Silva CRR, Vicente MC, Costa TF, Costa KNFM. Resilience and functional capacity of elderly people with diabetes mellitus. Rev Rene. 2018; 19:e3323. doi: http://dx.doi. org/10.15253/2175-6783.2018193323

6. Böell JEW, Silva DMGV, Hegadooren KM. Sociodemographic factors and health conditions associated with the resilience of people with chronic diseases: a cross sectional study. Rev Latino-Am Enfermagem. 2016; 24:e2786. doi: http://dx.doi. org/10.1590/1518-8345.1205.2786

7. Cecilio SG, Brasil LGB, Vilaça CP, Silva SMF, Vargas EC, Torres HC. Psychosocial aspects of living with diabetes mellitus in promoting self-care. Rev Rene. 2016; 17(1):44-51. doi: http://dx.doi. org/10.15253/2175-6783.2016000100007

8. Ye ZJ, Liang MZ, Qiu HZ, Liu ML, Hu GY, Zhu YF, et al. Effect of a multidiscipline mentor-based program, Be Resilient to Breast Cancer (BRBC), on female breast cancer survivors in mainland China - a randomized, controlled, theoretically-derived intervention trial. Breast Cancer Res Treat. 2016; 1583:509-22. doi: http://dx.doi.org/10.1007/ s10549-016-3881-1 
9. Pinchera B, Dellolacono D, Lawless CA. Best practices for patient self-management: implications for nurse educators, patient educators, and program developers. J Contin Educ Nurs. 2018; 49(9):43240. doi: http://dx.doi.org/10.3928/0022012420180813-09

10. Perim PC, Dias CS, Corte-Real NJ, Andrade AL, Fonseca AM. Análise fatorial confirmatória da versão Brasileira da Escala de Resiliência (ER - Brasil). Gerais (Univ Fed Juiz Fora) [Internet]. 2015 [citado 2019 jan 13]; 8(2):373-84. Available from:http://pepsic.bvsalud.org/pdf/gerais/ v8n2/v8n2a07.pdf

11. Michels MJ, Coral MHC, Sakae TM, Damas TB, Furlanetto LM. Questionário de Atividades de Autocuidado com o Diabetes: tradução, adaptação e avaliação das propriedades psicométricas. Arq Bras Endocrinol Metab. 2010; 54(7):64451. doi: http://dx.doi.org/10.1590/S000427302010000700009

12. Juliano MCC, Yunes MAM. Reflections on the social support network as a mechanism for the protection and promotion of resilience. Ambient Soc. 2014; 17(3):135-54. doi: http://dx.doi.org/10.1590/ S1414-753X2014000300009

13. Shu L, Shen XM, Li C, Zhang XY, Zheng PF. Dietary patterns are associated with type 2 diabetes mellitus among middle-aged adults in Zhejiang Province, China. Nutr J. 2017; 16(1):81. doi: http://dx.doi.org/10.1186/s12937-017-0303-0

14. Oliveira MSS, Oliveira ICC, Amorim MES, Otton R, Nogueira MF. Evaluation of therapeutic adherence of patients with diabetes mellitus type 2 . Rev Enferm UFPE on line [Internet]. 2014 [cited Sep 13, 2018]; 8(6):1692-701. Available from: https:// periodicos.ufpe.br/revistas/revistaenfermagem/ article/view/13643
15. Mena C, Sepulveda C, Ormazábal Y, Fuentes E, Palomo EU. Impact of walkability with regard to physical activity in the prevention of diabetes. Geospat Health. 2017; 12(2):595. doi: https://doi. org/10.4081/gh.2017.595

16. Barrile SR, Coneglian CB, Gimenes C. Conti MHS, Arca EA, Rosa Junior G, et al. Efeito agudo do exercício aeróbio na glicemia em diabéticos 2 sob medicação. Rev Bras Med Esporte. 2015; 21(5):360-33. doi: http://dx.doi. org/10.1590/1517-869220152105117818

17. Nogueira LCF, Medeiros ACT, Bittencourt GKGD, Nóbrega MML. Nursing diagnoses, outcomes and interventions to elderly patients with diabetes: a case study. Online Braz J Nurs. 2016; 15(2):30212.doi:https://doi.org/10.17665/16764285.20164964

18. Nishio I, Chujo M. Qualitative analysis of the resilience of adult Japanese patients with type 1 diabetes. Yonago Acta Med [Internet]. 2016 [cited Oct 13, 2018]; 59(3):196-203. Available from: https://www.ncbi.nlm.nih.gov/pmc/articles/ PMC5050268/pdf/yam-59-196.pdf

19. Crisologo PA, Lavery LA. Remote home monitoring to identify and prevent diabetic foot ulceration. Ann Transl Med. 2017; 5(21):430. doi: http:// dx.doi.org/10.21037/atm.2017.08.40

20. Chhetri JK, Zheng Z, Xu X, Ma C, Chan P. The prevalence and incidence of frailty in prediabetic and diabetic community-dwelling older population: results from Beijing longitudinal study of aging II (BLSA-II). BMC Getriatr. 2017; 17(47):1-8. doi: http://dx.doi.org/10.1186/s12877-017-0439-y 